\title{
MONITORIA ACADÊMICA EM PARASITOLOGIA HUMANA: UM RELATO DE EXPERIÊNCIA
}

\author{
ACADEMIC MONITORING OF HUMAN PARASITOLOGY: AN EXPERIENCE \\ REPORT
}

\author{
Francisco Patrício de Andrade Júnior, Vanessa Santos de Arruda Barbosa \\ Universidade Federal de Campina Grande
}

\begin{abstract}
The monitoring is a program that contributes to the quality of teaching in universities, seeking to offer the students the possibility to deepen and solve doubts about contents covered in the classroom. This study aimed to describe, through an experience report, the activities carried out during the monitoring of Human Parasitology discipline of the Academic Unit of Health, Federal University of Campina Grande, Campus Cuité between October 2016 and April 2017. During this period, it was possible to develop practical and theoretical activities with active discussions, resolution of exercise lists, identification of parasites and vectors through optical microscopes and stereomicroscopes, as well as production of support materials.
\end{abstract}

Key words: Health Education, Monitoring, Higher Education, Parasitology.

\section{Resumo}

A monitoria é um programa que contribui para a qualidade do ensino nas universidades, buscando oferecer aos estudantes a possibilidade de aprofundar e sanar dúvidas acerca de conteúdos vistos em sala de aula. O objetivo desse estudo foi descrever, através de um relato de experiência, as atividades realizadas durante a monitoria da disciplina de Parasitologia Humana da Unidade Acadêmica da Saúde, Universidade Federal de Campina Grande, Campus Cuité entre outubro de 2016 a abril de 2017. Nesse período, foi possível desenvolver atividades práticas e teóricas com discussões ativas, resolução de listas de exercícios, identificação de parasitas e vetores através de microscópios ópticos e estereomicroscópios, além da produção de materiais de apoio.

Palavras chave: Educação em Saúde, Monitoria, Ensino superior, Parasitologia. 
Introdução

A monitoria é um serviço pedagógico que contribui para a qualidade e eficácia do ensino nas universidades, buscando oferecer serviços aos estudantes que necessitam aprofundar conteúdos e sanar dúvidas acerca das matérias trabalhadas em sala de aula ${ }^{1}$.

A lei $n$ ㅇ 5540/68 fixa normas de organização e funcionamento da monitoria acadêmica no ensino superior, sendo determinado em seu Art. 41 que as universidades deverão criar funções de monitor para os seus respectivos cursos de graduaçao ${ }^{2}$.

$\mathrm{Na}$ Universidade Federal de Campina Grande (UFCG) a monitoria é um programa de iniciação à docência, mantido e coordenado pela Pró-Reitoria de Ensino, que proporciona, aos alunos de graduação, um espaço de aprendizagem objetivando não só a melhora da formação acadêmica, mas também maior efetividade e qualidade do ensino ${ }^{3}$.

A atividade envolve o acadêmico/monitor e o professor-orientador, sendo necessário ao aluno-monitor ter conhecimentos prévios acerca da disciplina na qual irá atuar ${ }^{4}$.

Sendo a monitoria um suporte importante aos estudantes, por esclarecer questionamentos e possibilitar maior êxito nas disciplinas em estudo, vê-se a necessidade de pesquisas acerca das atividades vivenciadas em monitorias, já que no Brasil esse tipo de estudo ainda é escasso, sobretudo na área da saúde podendo servir como subsídio para ampliação e melhoramento desse serviço disponibilizado a comunidade acadêmica ${ }^{5,6}$.

Desta forma, o presente estudo teve como objetivo descrever, através de um relato de experiência, as atividades realizadas durante a monitoria exercida na disciplina de parasitologia humana.

\section{Metodologia}

Estudo descritivo, do tipo relato de experiência, que foi realizado entre outubro de 2016 a abril de 2017 durante a vigência da monitoria na disciplina de Parasitologia Humana da Unidade Acadêmica da Saúde, Universidade Federal de Campina Grande, Campus Cuité.

\section{Relato de Experiência}

\section{Descrição da Disciplina}

A disciplina de Parasitologia Humana é ofertada semestralmente e se caracteriza por ser diurna, possuir quatro créditos (totalizando 60 horas por semestre) e ser de caráter teóricoprático, sendo obrigatória para os cursos de Farmácia e Nutrição. O desenvolvimento dá-se com aulas teóricas e práticas, as avaliações podem ser feitas através de provas teóricas, práticas e trabalhos realizados durante 0 semestre, havendo a participação de três monitores bolsistas.

\section{Atividades realizadas durante a monitoria}

As atividades realizadas durante a monitoria foram efetuadas no laboratório de Parasitologia, localizado na Universidade Federal de Campina Grande, Campus Cuité - PB.

O laboratório de Parasitologia possui armários, bancadas, bancos, pias, produtos para assepsia, ar-condicionado, quadro branco, microscópios ópticos e estereomicroscópios, centrífuga, estufa de secagem, geladeira, lâminas de parasitos em material permanente (parasitos e vetores) mantidos em meio líquido (formol $10 \%)$ e a seco (conservados em naftalina), vidrarias e reagentes. Contudo, pelo fato de - laboratório ser um local de risco biológico exigia-se o uso dos equipamentos de proteção individual a todos que ali adentrassem ${ }^{9}$.

O monitor dispunha de 12 horas semanais para desenvolver suas ações. As monitorias podiam ser realizadas de duas formas: 1) Durante as aulas práticas, juntamente com a docente, o monitor poderia esclarecer aos alunos dúvidas acerca de questões como morfologia, habitat e principais características dos parasitos estudados; 2) Fora dos horários de aulas práticas, o monitor poderia realizar atividades tanto de cunho teórico como prático, sendo essas agendadas por estudantes.

\section{Monitorias Teóricas}

Nas monitorias teóricas utilizaram-se como principais recursos, as listas de exercícios que abordavam questões como: características morfológicas, ciclo-biológico, habitat, sinais e sintomas, patogenia, epidemiologia e medidas profiláticas acerca dos parasitos e parasitoses estudadas, além da utilização de quadro, pincéis, livros e atlas que são disponibilizados pela instituição.

Inicialmente havia a resolução das listas de exercícios e após os estudantes tinham total liberdade para discutir o assunto abordado e fazer novos questionamentos, permitindo o desenvolvimento das relações interpessoais entre monitor e alunos. 
Dentre os conteúdos teóricos, alguns destacaram-se por ser de difícil absorção, havendo consequentemente, maior questionamento por parte dos alunos, tais como: amebas patogênicas e não-patogênicas, Trypanosoma cruzi e doença de Chagas, Complexo Leishmania e leishmanioses tegumentar e visceral.

É relevante detectar as principais dificuldades enfrentadas pelos estudantes, pois isso possibilita e estimula o desenvolvimento de estratégias e ações para auxiliá-los.

\section{Monitorias Práticas}

Os principais materiais utilizados nas monitorias práticas foram: atlas, lâminas contendo os parasitos, microscópios ópticos e estereomicroscópios.

Para essas atividades, havia o preparo do local com as lâminas focalizadas nos microscópios. Junto ao microscópio, o estudante analisava as lâminas e, além disso, desfrutava da experiência de manipular os microscópios ópticos e estereomicroscópios disponíveis no laboratório. Quando necessário, os alunos recorriam ao monitor para sanar dúvidas, principalmente sobre morfologia dos parasitos.

\section{Produção de Material Didático}

Durante as monitorias práticas foi possível perceber que os estudantes possuíam algumas dificuldades em aprender as características morfológicas de parasitos e vetores, deste modo em conjunto com a docente foram elaborados roteiros de aula prática, objetivando contribuir diretamente com o aprendizado como um todo e também servir como material de apoio para as provas práticas.

Ao todo, foram elaborados dois roteiros, um para a unidade III e outro para unidade IV. O primeiro roteiro contém informações acerca dos parasitas Schistosoma mansoni, Taeniasolium e $T$. saginata, Hymenolepis nana e $H$. diminuta, Ascaris lumbricoides, Enterobiusvermicularis e Trichuristrichiura, enquanto que o segundo roteiro contém informações sobre Ancilostomatidae, Strongyloidesstercoralis e vetores: triatomíneos, flebotomíneos, mosquitos e ectoparasitos: miíases, ácaros, carrapatos, piolhos e pulgas. Para a elaboração desses materiais, livros e atlas de parasitologia foram utilizados. Em relação as imagens utilizadas, essas foram obtidas a partir de fotografias de lâminas de parasitos e vetores, disponíveis no laboratório de Parasitologia (Figura 1).

Figura 1. Demonstração de como as informações dos roteiros eram representadas e organizadas.

1. Schistosoma mansoni - Adulto

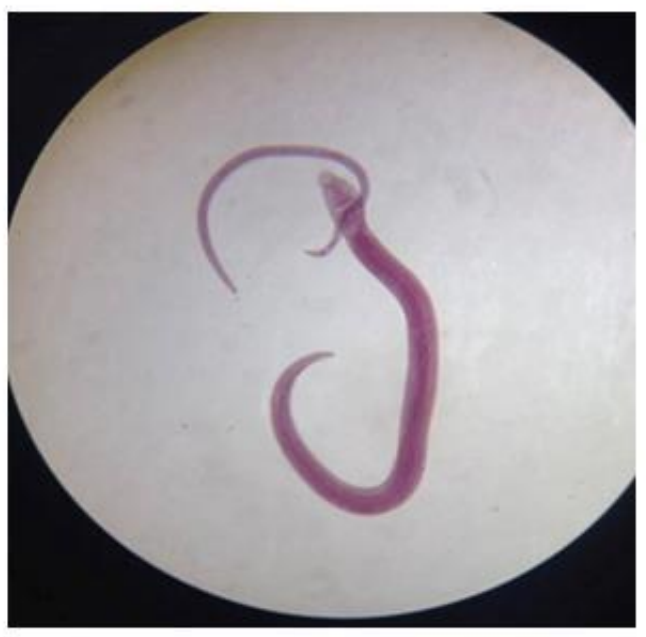

Forma evolutiva: Adulto - Macho e Fêmea.

Habitat: Sistema porta.

Características: Macho: $1 \mathrm{~cm}$ de comprimento, tem cor esbranquiçada, ventosa oral, ventosa ventral, canal ginecóforo e lobos testiculares. Fêmea: mede cerca de $1,5 \mathrm{~cm}$ de comprimento, tem cor mais escura devido ao ceco com sangue semidigerido, ventosa oral, ventosa ventral (acetábulo), vulva, útero ( com um ou dois ovos), ovários, glândulas vitelogênicas (ou vitelinas) e ceco.
Após as correções dos roteiros, o material era enviado por e-mail aos estudantes da disciplina, permitindo que estes estudassem por meio de computadores, celulares e pudessem ainda imprimi-los, o que é um recurso bastante vantajoso, como enfatizado por Corrêa ${ }^{7}$ o material impresso é de fácil transporte, permite anotações e pode ser lido em diversos locais, a qualquer momento, respeitando o ritmo de aprendizado do aluno. monitor

Percepções e dificuldades enfrentadas pelo

O monitor pode ser definido como aquele que acompanha os estudantes à distância e fica disponível para resolver dúvidas que eventualmente possam surgir ${ }^{8}$. Entretanto, esse 
conjunto de ações me permitiu, não somente aprimorar meus conhecimentos, mas também a desenvolver diferentes formas de comunicação para o repasse adequado das informações a serem esclarecidas.

Além disso, foi enriquecedora a experiência de desenvolver roteiros para aulas e provas práticas, uma vez que me permitiu conhecer novas informações relevantes acerca dos parasitos e usufruir de inovação para transmitir os assuntos aos estudantes.

No que tange ao fortalecimento curricular, a monitoria foi de extrema relevância, pois esta pontua como atividades complementares em processos seletivos.

Nesse sentido, alguns estudos ${ }^{10,11,12}$ ressaltam que os estudantes que exercem a função de monitor tornam-se mais proativos e criativos, têm maior senso de responsabilidade, boa comunicação e maior aproximação da rotina do ensino.

Em relação às dificuldades, a principal está relacionada a infraestrutura do laboratório, por ser um ambiente pequeno para a quantidade de discentes e serem insuficientes os microscópios, sendo interessante a ampliação desse local e compra de novos equipamentos.

\section{Considerações Finais}

A experiência adquirida no período foi positiva, pois foi possível aprofundar e obter novos conhecimentos na área da parasitologia humana, exercer a atividade docente, aprimorar a comunicação, construir relações interpessoais e desenvolver a empatia

\section{Referências}

1. Haag GS, Kolling V, Silva E, Melo SCB, Pinheiro $M$. Contribuições da monitoria no processo ensino aprendizagem em enfermagem. RevBrasEnferm. 2008; 61(2):215-20.

2. Assis F, Borsatto AZ, Silva PDD, Peres PL, Rocha PR, Lopes GT. Programa de monitoria acadêmica: percepções de monitores e orientadores. R Enferm UERJ. 2006; 14(3): 391-97.

3. Universidade Federal de Campina Grande. Monitoria. [Citado 2016 Jun 29]. Disponível em: http://pre.sti.ufcg.edu.br/pre/monitoria.

4. Oliveira JLAP, Souza SV. Relato de experiência na atividade de monitoria desenvolvida na disciplina de estágio básico de observação do desenvolvimento: um texto que se escreve a quatro mãos. Cad Acad. 2012; 4(1):3546.

5. Dantas OM. Monitoria: fonte de saberes à docência superior. RevBrasEstudPedagog. 2014; 95(241): 567-89.

6. Magalhães LD, Januário IS, Maia AKF. A monitoria acadêmica da disciplina de cuidados críticos para enfermagem: um relato de experiência. Revista da Universidade Vale do Rio Verde. 2014;12(2):556-65.

7. Corrêa MA. Os materiais didáticos como recursos fundamentais de potencializaçãoda qualidade do ensino e aprendizagem na EAD. Tecnologias para Competitividade Industrial. 2013;6(1):125-40.

8. Nunes JT, França DJR, Felix RS, Fernandes MNF. Processo de ensino-aprendizagem no desempenho das atividades de monitoria: relato de experiência. RevEnferm UFPE online.2014;8(11):4165-169.

9. Carvalho IS, Lima Neto AV, Freitas Segundo FC, Carvalho GRP, Nunes VMA. Monitoria em semiologia e semiotécnica para a enfermagem: um relato de experiência. Ver Enferm UFSM. 2012; 2(2): 464-71.

10. Figueiredss TC, Frigo LF. Percepções acerca da monitoria acadêmica na disciplina de fisioterapia e a saúde da mulher.RevEpidemiolControllnfect. 2014; 4(1):34-35.

11. Silva CB, Lacerda AM. Monitoria na disciplina investigação em psicologia I: um relato de experiência. Hum@nAE. 2015; 9(1).

12. Barbosa MG, Azevedo MEO, Oliveira MCA. Contribuições da monitoria acadêmica para o processo de formação inicial docente de licenciandas do curso de ciência biológica da FACEDI/UECE. Revista da SBENBio. 2014 out; (7):5471-479.

\section{Endereço para Correspondência}

Universidade Federal de Campina Grande UFCG

e-mail: juniorfarmacia.ufcg@ outlook.com

Recebido em 08/05/2017

Aprovado em 10/08/2017

Publicado em 15/09/2017 